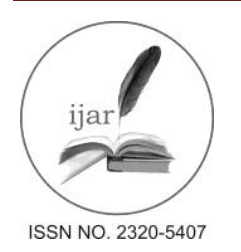

Journal homepage: http://www.journalijar.com
Journal DOI: 10.21474/IJAR01

INTERNATIONAL JOURNAL

RESEARCH ARTICLE

\title{
IMPORTANCE OF 24-HR AMBULATORY BLOOD PRESSURE MONITORING IN CHRONIC KIDNEY DISEASE PROGRESSION.
}

\author{
Lekharaj Choudhary ${ }^{1}$, Arvind Gupta ${ }^{2}$, Upma Narayan ${ }^{3}$, Yashaswi $^{4}$, Nikhil Gupta $^{5}$, Parag Saraswat ${ }^{5}$, \\ Alankar Tiwari, ${ }^{5}$, ikesh Mishra ${ }^{5}$, Indramani Prakash ${ }^{5}$. \\ 1. MD Medicine, Department Of Medicine; M.L.N. Medical College and SRN Hospital, Allahabad, India. \\ 2. Professor, Department Of Medicine; M.L.N. Medical College and SRN Hospital, Allahabad, India. \\ 3. D Phil. Medical Microbiology; Tejas Microdiagnostics, Allahabad, India. \\ 4. Junior Resident, Department Of Medicine; M.L.N. Medical College and SRN Hospital, Allahabad, India. \\ 5. MD Medicine, Department Of Medicine; M.L.N. Medical College and SRN Hospital, Allahabad, India.
}

\section{Manuscript Info}

Manuscript History:

Received: 15 May 2016

Final Accepted: 22 June 2016

Published Online: July 2016

Key words:

24-hr Ambulatory blood pressure monitoring, CKD patients, and prognostic marker.

*Corresponding Author

Lekharaj Choudhary.

\begin{abstract}
Background- Hypertension is one of the leading risk factor for Chronic Kidney Disease and non-dipper pattern of blood pressure is very common in chronic kidney disease patients and affects the renal outcome in these patients.Ambulatory blood pressure monitoring assists in targeting this population. Methods- Total 160 non diabetic hypertensive patients were enrolled between 10/04/14 to 15/05/15 at M.L.N. Medical College and SRN Hospital, Allahabad. Out of them 80 were CKD patients who were taken as cases and remaining 80 patients were non CKD and taken as controls. Ambulatory blood pressure monitoring, clinic BP, eGFR, and other clinical data were collected for 1 year duration. Statistical analysis was done by using unpaired t-test for independent variables. Results- out of 160 non diabetic hypertensive patients, $48(60 \%)$ cases and $28(35 \%)$ controls were found nondippers, while remaining 32(40\%) cases and 52(65\%) controls were have dipper BP pattern. Patients with non-dipping BP pattern had the worst renal function $(\mathrm{P}<0.05)$. The eGFR shown significant relationship with the nocturnal BP. Conclusion- Ambulatory blood pressure measurement allows a better risk stratification compared to clinic blood pressure measurement. Non-dipping status is closely related to severe renal damage in CKD patients. Hence 24-hr ABPM can be used as prognostic markers in non diabetic CKD patients, and Lowering of nocturnal BP will reduce the risk of renal damge in these patients.
\end{abstract}

Copy Right, IJAR, 2016,. All rights reserved.

\section{Introduction:-}

Hypertension and loss of diurnal BP variation i.e. non-dipping pattern is responsible for rapid progression of renal disease. Normally, nocturnal dip (\% fall in night time systolic blood pressure compared to daytime systolic blood pressure) of more than $10 \%$ occurs in night-time and this nocturnal dip is due to fall in sympathetic nervous system activity during night. ${ }^{1}$ Patients having less than normal nocturnal decline in night-time systolic blood pressure have been termed non-dippers, while those with normal diurnal BP variation are termed dippers. Dipping ratio (mean night time SBP to mean day time SBP ratio) is more than 0.9 for non-dippers while it is 0.8 to 0.9 for dippers. $^{2}$

Blunting or loss of this diurnal variation of BP (i.e. non-dipping) occurs in CKD patients due to increased sympathetic nervous system activity, volume expansion, sleep apnoea, low level of physical activity during daytime, poor sleep quality and use of antihypertensive drugs. ${ }^{3-9}$ Hence twenty four hour mean systolic BP remains high in subjects with non-dipper BP pattern. Hence, some of the increased target organ damage risk i.e. renal and cardiovascular disease progression associated with elevated nocturnal blood pressures (non-dipping blood pressure 
profile) may simply be due to the greater 24-h BP load in non-dippers as compared to dippers.(10-13) And 24-hr ambulatory blood pressure monitoring (ABPM) is superior to clinic BP monitoring in predicting the risk in hypertensive CKD patients. ${ }^{14-16}$

\section{Methods:-}

The present case control study was conducted in M.L.N. Medical College and associated SRN hospital, Allahabad between 10/04/14 to 15/05/15 to analyse the impact of diurnal blood pressure profile variation (dipping or nondipping pattern) on renal damage risk in non diabetic hypertensive chronic kidney disease (CKD) patients.

The subjects included in the current study were non diabetic hypertensive patients between the age group of 18 to 60 years of either sex attending nephrology OPD in SRN Hospital Allahabad and consented for the study. Out of total enrolled patients, cases taken in our study were Non diabetic hypertensive (Clinic blood pressure >140/90 $\mathrm{mmHg}$, while ambulatory 24-hr blood pressure $>130 / 80 \mathrm{mmHg}$ ) CKD patients of stage 2 to 5 as per KDIGO guidelines 2012, while control group comprised of age matched non-diabetic hypertensive non CKD volunteers. Out of total 160 enrolled subjects, 80 were cases and 80 were controls. Twenty four hour ABPM, and eGFR (estimated glomerular filtration rate) were monitored for total duration of 1 year. Statistical analysis was done by using unpaired $t$ test for independent variables to find out the association between non dipping blood pressure pattern and raised risk of target organ damage in non diabetic hypertensive CKD patients.

Any patient having changes in antihypertensive therapy 2 weeks before ABPM, true normotensive persons (BP<130/80 mmHg without antihypertensive therapy), patients on dialysis treatment or renal transplantation, diabetic CKD patients, patients with renal transplant, inadequate ABPM (Number of recordings $<14$ and during day and $<7$ during night respectively) and patients having established cardio vascular disease (valvular heart disease, cardiomyopathy, acute coronary syndrome) except hypertension were excluded from the study.

On the first visit to the OPD, clinic BP of all the participants was measured 3 times at 5 minute intervals. The clinic $\mathrm{BP}$ taken in this study was a mean of the 6 values recorded in the 2 consecutive days in which the ABPM device for 24-hr ambulatory BP monitoring was installed and removed. The installed ABPM device recorded systolic blood pressure and diastolic blood pressure (SBP and DBP) every $30 \mathrm{~min}$ between $7 \mathrm{am}$ to $11 \mathrm{pm}$ (active period) and every $60 \mathrm{~min}$ between $11 \mathrm{pm}$ to 7 am (passive period). The BP was considered at target when daytime and night-time values were less than $135 / 85 \mathrm{mmHg}$ and less than $120 / 70 \mathrm{mmHg}$ respectively. After this; dipping status (ratio of mean night time to mean day time SBP) was calculated. Then cases and controls were classified into dipper and non-dipper category depending upon the dipping ratio. Dippers have dipping ratio between 0.8-0.9 while for nondippers this ratio is 0.9-1.0. Investigations collected on their first visit (zero month) were serum creatinine, serum urea, eGFR (Cockcroft-Gault formula), USG abdomen (renal size and echo-texture), fasting blood sugar, HbA1C, serum intact PTH, and haemoglobin. They followed up every month for complete 1 year. To assess the effect of hypertension on renal functions \& their eGFR were recorded monthly. The Graph Pad software version 6.0 was used for statistical analysis. The numerical data was compared by using unpaired $t$ test for independent variables and the level of significance was considered at $\mathrm{P}$ value of 0.05 .

\section{Results:-}

Baseline characteristics of patients:-

The demographic and clinical data of the patients at the time of starting the study are listed in Table 1. Among the total 160 age matched hypertensive non-diabetic patients of either sex, 80 were CKD (cases), while 80 were non CKD (controls).

Prevalence of non-dipping pattern and increased risk of renal \& cardiovascular events in study population:Out of 80 cases, 48 were non-dippers (60\%) while among 80 controls only 28 (35\%) were non-dippers (Table1). During follow up, 22 cases (4 dippers and 18 non-dippers) and 4 controls (all 4 were non-dippers) were lost to follow up after their first clinic visit due to having either renal or cardiovascular end points (Table2). Non-dipping pattern of BP is more prevalent in CKD patients and incidences of renal \& cardiovascular events are high in non-dippers compared to dippers and even more in CKD patients compared to non CKD patients. Among cases 4 dippers \& 12 non-dippers had to undergo haemodialysis while 4 non-dippers developed MI (myocardial infarction) and 2 non-dipper developed AF (atrial fibrillation); while among controls 2 dipper \& 6 non-dipper turned into CKD during follow up while 2 non-dipper developed MI \& 2 non-dipper had to undergo haemodialysis due to ARF (acute renal failure). 
Effect of non-dipping blood pressure pattern on renal (eGFR) functions of study population:-

Table 3 shows the effect of non-dipping blood pressure pattern on eGFR after 1 year of follow up. Among cases at baseline (0 month), non-dippers had the mean eGFR $(\mathrm{ml} / \mathrm{min} / 1.73 \mathrm{~m} 2)$ of $80.46 \pm 4.45$ and dippers had $82.28 \pm 3.19$. After 1 year of follow up, the mean eGFR of non-dippers and dippers decreased to $53.33 \pm 4.68$ and $66.35 \pm 4.19$ respectively. The decrement in mean eGFR of cases after 1 year of follow up was more in non-dippers as compared to dippers and was statistically significant also ( $\mathrm{p}$ value $=0.001)$. Among controls at baseline $(0 \mathrm{month})$, non-dippers had the mean eGFR $(\mathrm{ml} / \mathrm{min} / 1.73 \mathrm{~m} 2)$ of $102.3 \pm 4.63$ and dippers had $104.73 \pm 5.72$. After 1 year of follow up, the mean eGFR of non-dippers and dippers decreased to $91.42 \pm 7.73$ and $98.88 \pm 7.52$ respectively. The decrement in mean eGFR of controls after 1 year of follow up was greater in non-dippers than dippers and was statistically significant also ( $\mathrm{p}$ value $=0.007$ ).

Data given in Table 3 shows that decrement in mean eGFR after 1 year of follow up was more in CKD patients as compared to non CKD patients. The Non-dipping pattern of blood pressure in hypertensive CKD patients has more significant relationship with decline in eGFR or progression of CKD as compared to dipping pattern of BP.

Night-time SBP compared to daytime SBP causes more target organ damage risk:-

After analysing the effect of daytime and nigh-time SBP on renal function of cases and controls we found that eGFR declined significantly ( $\mathrm{p}$ value $<0.05$ ) among cases who had mean daytime and night-time SBP more than 135 and $120 \mathrm{~mm} \mathrm{Hg}$ respectively as compared to cases having mean daytime and night-time SBP in the range of 125-135 and 110-120 respectively. And among controls, patients who had mean daytime and night-time SBP more than 145 \& $135 \mathrm{~mm} \mathrm{Hg}$ respectively had significant decline ( $\mathrm{p}$ value $<0.05$ ) in eGFRcompared to controls having mean daytime and night-time SBP respectively in the range of $120-145$ and 110-135 mm Hg.

Table 4, 5, 6, 7, 8 and 9 shows that eGFRin patients decreases as the mean daytime and night-time SBP increases but this decline is more in CKD patients as compared to non CKD patients, i.e. any degree of increment in blood pressure causes more target organ damage in CKD patients as compared to non CKD patients. Rise in night-time SBP leads to more increment in target organ damage risk when compared to similar level of rise in daytime SBP.

Table 1:- Demographic parameters of patients.

\begin{tabular}{|c|c|c|}
\hline Parameters & $\begin{array}{l}\text { CKD patients } \\
\text { (Cases) } n=80\end{array}$ & Non CKD patients (controls) $n=80$ \\
\hline Number of males & 58 & 64 \\
\hline Number of females & 22 & 16 \\
\hline Mean age in years \pm SD & $48.58 \pm 7.94$ & $47.35 \pm 9.78$ \\
\hline Mean clinic BP $(\mathrm{mmHg}) \pm \mathrm{SD}$ & $146 \pm 17 / 82 \pm 10$ & $142 \pm 15 / 83 \pm 12$ \\
\hline Mean ambulatory $\mathrm{BP}(\mathrm{mmHg}) \pm \mathrm{SD}$ & $\begin{array}{l}\text { Mean 24hr-136 } \pm 12 / 78 \pm 8 \\
\text { Daytime- } 144 \pm 19 / 81 \pm 9 \\
\text { Nighttime-130 } 22 / 76 \pm 11\end{array}$ & $\begin{array}{l}\text { Mean 24hr- } 133 \pm 9 / 75 \pm 6 \\
\text { Daytime- } 136 \pm 16 / 79 \pm 7 \\
\text { Nighttime- } 126 \pm 17 / 71 \pm 13\end{array}$ \\
\hline Dippers (n) & 32 & 52 \\
\hline Non-dippers (n) & 48 & 28 \\
\hline
\end{tabular}

Table 2:- Prevalence of renal and cardiac events in CKD (cases) and non CKD (controls) patients.

\begin{tabular}{|c|c|c|c|c|}
\hline \multirow{2}{*}{ Dipping status } & \multicolumn{2}{|c|}{ CKD (Cases) } & Non CKD (Controls) \\
\cline { 2 - 5 } & $\begin{array}{c}\text { Renal } \\
\text { Events }\end{array}$ & $\begin{array}{c}\text { Cardiac } \\
\text { events }\end{array}$ & $\begin{array}{c}\text { Renal } \\
\text { events }\end{array}$ & $\begin{array}{r}\text { Cardiac } \\
\text { events }\end{array}$ \\
\hline Dippers (n) & $4 \mathrm{HD}$ & None & $\begin{array}{c}2 \text { turned } \\
\text { into CKD }\end{array}$ & None \\
\hline Non-dippers (n) & $12 \mathrm{HD}$ & $\begin{array}{c}4 \text { acute MI } \\
2 \mathrm{AF}\end{array}$ & $\begin{array}{c}2 \mathrm{HD} \\
6 \text { turned } \\
\text { into CKD }\end{array}$ & 2 acute MI \\
\hline
\end{tabular}


Table 3:- Mean eGFR(ml/min $\left./ 1.73 \mathrm{~m}^{2}\right)$ values at zero month and at the end of 1 year and the decline in mean eGFRat the end of 1 year in dippers and non-dippers of CKD and non CKD patients.

\begin{tabular}{|l|c|c|c|c|}
\hline \multirow{2}{*}{ Parameters } & \multicolumn{2}{c|}{ CKD (cases) } & \multicolumn{2}{c|}{ Non CKD (controls) } \\
\cline { 2 - 5 } & Dippers & Non-dipper & Dippers & Non-dippers \\
\hline Mean eGFR \pm SD at 0 month & $82.28 \pm 3.19$ & $80.46 \pm 4.45$ & $104.73 \pm 5.7$ & $102.3 \pm 4.63$ \\
\hline $\begin{array}{l}\text { Mean eGFR } \pm \text { SD after 1 year } \\
\text { follow up }\end{array}$ & $66.35 \pm 4.19$ & $53.33 \pm 4.68$ & $98.88 \pm 7.52$ & $91.42 \pm 7.73$ \\
\hline $\begin{array}{l}\text { Decline in mean eGFR after 1 } \\
\text { year }\end{array}$ & 15.65 & 27.13 & 5.85 & 10.91 \\
\hline
\end{tabular}

Table 4:- Mean eGFR $\left(\mathrm{ml} / \mathrm{min} / 1.73 \mathrm{~m}^{2}\right)$ values at zero month and at the end of 1 year and the decline in mean eGFR at the end of 1 year in CKD and non CKD patients having mean daytime SBP of $125-135 \mathrm{~mm} \mathrm{Hg}$. (eGFR $\mathrm{inml} / \mathrm{min} / 1.73 \mathrm{~m}^{2}$ ).

\begin{tabular}{|c|c|c|}
\hline Parameters & Cases $($ CKD) $\mathbf{n = 1 5}$ & Control $(\mathbf{n o n}$ CKD) $\mathbf{n = 2 8}$ \\
\hline Mean eGFR \pm SD at 0 month & $81.23 \pm 3.12$ & $103.14 \pm 2.50$ \\
\hline Mean eGFR \pm SD after 1 year & $78.21 \pm 4.04$ & $101.22 \pm 3.45$ \\
\hline Decline in mean eGFR after 1 year & 3.02 & 1.92 \\
\hline P value & 0.82 & 0.47 \\
\hline
\end{tabular}

Table 5:- Mean eGFR $\left(\mathrm{ml} / \mathrm{min} / 1.73 \mathrm{~m}^{2}\right)$ values at zero month and at the end of 1 year and the decline in mean eGFR at the end of 1 year in CKD and non CKD patients having mean daytime SBP of $135-145 \mathrm{~mm} \mathrm{Hg}$. (eGFR in $\left.\mathrm{ml} / \mathrm{min} / 1.73 \mathrm{~m}^{2}\right)$.

\begin{tabular}{|c|c|c|}
\hline Parameters & Cases $($ CKD) $\mathbf{n = 2 8}$ & Control (non-CKD) $\mathbf{n = 4 0}$ \\
\hline Mean eGFR \pm SD at 0 month & $79.29 \pm 3.66$ & $99.74 \pm 2.32$ \\
\hline Mean eGFR + SD after 1 year & $75.26 \pm 3.57$ & $97.40 \pm 1.43$ \\
\hline Decline in mean eGFR after 1 year & 4.03 & 2.34 \\
\hline P value & 0.04 & 0.169 \\
\hline
\end{tabular}

Table 6:- Mean eGFR $\left(\mathrm{ml} / \mathrm{min} / 1.73 \mathrm{~m}^{2}\right)$ values at zero month and at the end of 1 year and the decline in mean eGFR at the end of 1 year in $\mathrm{CKD}$ and non CKD patients having mean daytime SBP of $>145 \mathrm{~mm} \mathrm{Hg}$. (eGFR in $\mathrm{ml} / \mathrm{min} / 1.73 \mathrm{~m}^{2}$ )

\begin{tabular}{|c|c|c|}
\hline Parameters & Cases(CKD) $\mathbf{n = 1 5}$ & Control (non CKD) $\mathbf{n = 8}$ \\
\hline Mean eGFR \pm SD at 0 month & $77.58 \pm 3.62$ & $99.88 \pm 2.20$ \\
\hline Mean eGFR \pm SD after 1 year & $52.07 \pm 1.88$ & $85.48 \pm 3.86$ \\
\hline Decline in mean eGFR after 1 year & 25.51 & 0.003 \\
\hline P value & 0.00069 & 14.4 \\
\hline
\end{tabular}

Table 7:- Mean eGFR $\left(\mathrm{ml} / \mathrm{min} / 1.73 \mathrm{~m}^{2}\right)$ values at zero month and the end of 1 year and the decline in mean eGFR at the end of 1 year in CKD and non CKD patients having mean night-time SBP of $110-120 \mathrm{~mm} \mathrm{Hg}$. (eGFR in $\mathrm{ml} / \mathrm{min} / 1.73 \mathrm{~m}^{2}$ )

\begin{tabular}{|c|c|c|}
\hline Parameters & Cases(CKD) $\mathbf{n = 2 0}$ & Control (non CKD) $\mathbf{n = 4 8}$ \\
\hline Mean eGFR \pm SD at 0 month & $85.46 \pm 3.63$ & $102.43 \pm 1.40$ \\
\hline Mean eGFR \pm SD after 1 year & $80.18 \pm 1.21$ & $100.81 \pm 1.30$ \\
\hline Decline in mean eGFR after 1 year & 5.28 & 1.62 \\
\hline P value & 0.07 & 0.27 \\
\hline
\end{tabular}


Table 8:- Mean eGFR $\left(\mathrm{ml} / \mathrm{min} / 1.73 \mathrm{~m}^{2}\right)$ values at zero month and the end of 1 year and the decline in mean eGFR at the end of 1 year in CKD and non CKD patients having mean night-time SBP of $120-135 \mathrm{~mm} \mathrm{Hg}$. (eGFR in $\mathrm{ml} / \mathrm{min} / 1.73 \mathrm{~m}^{2}$ )

\begin{tabular}{|c|c|c|}
\hline Parameters & Cases(CKD) $\mathbf{n = 2 7}$ & Control (non CKD) $\mathbf{n = 1 8}$ \\
\hline Mean eGFR \pm SD at 0 month & $75.48 \pm 2.13$ & $101.02 \pm 2.76$ \\
\hline Mean eGFR \pm SD after 1 year & $57.75 \pm 0.7$ & $99.41 \pm 3.02$ \\
\hline Decline in mean eGFR after 1 year & 17.73 & 1.61 \\
\hline P value & 0.0009 & 0.07 \\
\hline
\end{tabular}

Table 9:- Mean eGFR $\left(\mathrm{ml} / \mathrm{min} / 1.73 \mathrm{~m}^{2}\right)$ values at zero month and at the end of 1 year and the decline in mean eGFR at the end of 1 year in CKD and non CKD patients having mean night-time $\mathrm{SBP}$ of $>135 \mathrm{~mm} \mathrm{Hg}$. ( eGFR in $\mathrm{ml} / \mathrm{min} / 1.73 \mathrm{~m} 2$ )

\begin{tabular}{|c|c|c|}
\hline Parameters & Cases(CKD) $\mathbf{n = 1 1}$ & Control (non CKD) n= 10 \\
\hline Mean eGFR \pm SD at 0 month & $75.45 \pm 3.76$ & $98.50 \pm 4.95$ \\
\hline Mean eGFR \pm SD after 1 year & $46.87 \pm 2.35$ & $80.23 \pm 3.05$ \\
\hline Decline in mean eGFR after 1 year & 28.58 & 18.27 \\
\hline P value & 0.0005 & 0.007 \\
\hline
\end{tabular}

\section{Discussion and Conclusions:-}

Previous studies have demonstrated that 24-hr ambulatory blood pressure monitoring is an important prognostic marker in hypertensive patients. ${ }^{14-16}$ Present study is done to assess the role of ABPM as a prognostic marker in non diabetic hypertensive CKD patients. The results of our study confirm the significance of 24-hr ambulatory BP monitoring in identifying or refuting the non-dipping pattern of BP or significant hypertension when compared with outpatient clinic BP measurement, as mentioned in a number of previous studies. The results of our study shows that non-dipping raises the target organ damage risk in non diabetic hypertensive CKD patients and the increment in risk is more in CKD patients as compared to non CKD patients.

Minutolo R et al. evaluated the Prognostic Role of Ambulatory Blood Pressure Measurement in Patients with Nondialysis Chronic Kidney Disease and concluded that Office measurement of BP did not predict the risk of the renal or cardiovascular end point. Patients who were non-dippers and those who were reverse dippers had a greater risk of both end points. The result of their study demonstrates that the predictive role of ABPM is independent of other risk factors, such as diabetes mellitus, cardiovascular disease, proteinuria, haemoglobin level, and GFR. They conducted a prospective cohort study in $436 \mathrm{CKD}$ patients (non-dialysis) to show the prognostic efficacy of ABPM (day \& night SBP \& DBP) in comparison with office measurements and they found that high nocturnal BP leads to increased renal and cardiovascular risk in CKD patients. ${ }^{15}$ Similarly in the present case control study, ABPM correlated more significantly with worsening of renal function than clinic BP in non diabetic hypertensive CKD patients.

Davidson $\mathrm{MB}$ et al. predicted the association of impaired diurnal blood pressure variation with a subsequent decline in glomerular filtration rate and concluded that blunted diurnal blood pressure variation is associated with a subsequent deterioration in renal function that is independent of SBP load and other risk factors for renal impairment. $^{17}$

Tripepi et al found that, 24-h systolic BP was also greater in subjects with higher night/day systolic ratios. Hence, some of the increased target organ damage risk associated with elevated nocturnal pressures (non-dipping) may simply be due to the greater $24-\mathrm{h}$ BP load associated with this elevation. ${ }^{14}$ This is consistent with our findings that Non-dippers have overall increased risk for target organ damage because of the greater 24-hr blood pressure load as a result of elevated nocturnal blood pressure.

Agarwal R et al. also concluded that Systolic ambulatory BP and non-dipping are independent predictors for ESRD after adjusting for clinic BP. ${ }^{16}$

In the present study we found that a non-dipper BP pattern was independently correlated with kidney damage in CKD patients. A high BP at night (non-dippers) impacts the heart, vasculature, and kidney, boosting damage and 
increasing risk of developing clinical events in CKD patients.In the present study, after 1 year of follow up it was not surprising to find that in CKD patients with non-dipper BP pattern the decrement in eGFR (ml/min/1.73m2) was 27.13 while the patients with dipping status had decrement of only 15.65 in eGFR. Therefore, lowering nocturnal BP might help to reduce renal death risk in non diabetic CKD patients who have non-dipping pattern of BP. In this study non-dippers were found to have lower eGFR or more rapid progression of CKD in comparison to dippers. As 24-hr ABPM can be used as a helping parameter for adequate control of hypertension, and consequently control of nocturnal BP will lead to reduction in the risk of renal death or slow down the disease progression in CKD patients. From our study it is very clear that 24-hr ABPM can be used as a prognostic marker in predicting the risk of morbidity and mortality in non diabetic hypertensive CKD patients.

In non diabetic hypertensive CKD patients, ambulatory blood pressure measurement allows a better risk stratification compared to clinic blood pressure measurement by identifying the dipping or non-dipping pattern of BP.Non-dipping blood pressure pattern is more prevalent in CKD patients. Rise in night-time SBP leads to more increment in target organ damage risk when compared to similar level of rise in daytime SBP. Non-dipping BP pattern is strongly related with increased target organ damage risk in non diabetic hypertensive CKD patients, and reduction in nocturnal $\mathrm{BP}$ will reduce this renal damage risk and improves the outcome.

\section{References:-}

1. Verdecchia P, Schillaci G, Guerrieri M, Gatteschi C, Benemio G, Boldrini F et al.Circulation. 1990 Feb;81(2):528-36.

2. O’Brien ESheridanJO’Malley K Dippers and non-dippers [letter]. Lancet 1988;2397

3. Sherwood A, Steffen PR, Blumenthal JA, Kuhn C, Hinderliter AL. Nighttime blood pressure dipping: the role of the sympathetic nervous system. Am J Hypertens. 2002;15:111-118

4. O'Shea JC, Murphy MB. Nocturnal blood pressure dipping: a consequence of diurnal physical activity blipping? Am J Hypertens 2000;13:601-6.

5. Uzu T, Ishikawa K, Fujii T, Nakamura S, Inenaga T, Kimura G: Sodium restriction shifts circadian rhythm of blood pressure from nondipper to dipper in essential hypertension. Circulation 1997;96:1859-1862.

6. Pedullà M, Silvestri R, Lasco A, Mento G, Lanuzza B, Sofia L et al. Sleep structure in essential hypertensive patients: differences between dippers and non-dippers. Blood Press 1995;4:232-237.

7. Kuhlmann U, Becker HF, Birkhahn M, Peter JH, von Wichert P, SchütterleS, et al. Sleep-apnea in patients with end-stage renal disease and objective results. ClinNephrol 2000;53: 460-466.

8. Hermida, RC, Calvo, C, Ayala, DE. Relationship between physical activity and blood pressure in dipper and non-dipper hypertensive patients.J Hypertens. 2002;20:1097-1104.

9. Fukuda M, Munemura M, Usami T, Nakao N, Takeuchi O, Kamiya. Nocturnal blood pressure is elevated with natriuresis and proteinuria as renal function deteriorates in nephropathy. Kidney Int2004; 65: 621-625.

10. Fagard RH, Celis H, Thijs L, Staessen JA, Clement DL, De Buyzere ML. Daytime and nighttime blood pressure as predictors of death and cause-specific cardiovascular events in hypertension. Hypertension 2008;51(1)55- 61.

11. Tilea I, Tatar C.M., Tatar R, Voidazan S, Bocicor E.A., Xantus T. Left ventricular systolic dysfunction and chronic kidney disease in hypertensive patients. Journal of Hypertension: June 2015 - Volume 33 - Issue > PP.04.03:

12. White WB. Ambulatory blood pressure as a predictor of target organ disease and outcome in the hypertensive patient. Blood Press Monit 1999;4181- 184

13. Ohkubo T, Imai Y, Tsuji I, Nagai K, Watanabe N, Minami N et al. Relation between nocturnal decline in blood pressure and mortality: the Ohasama Study. Am J Hypertens 1997;101201- 1207

14. Tripepi G, Fagugli RM, Dattolo P, Parlongo G, Mallamaci F, Buoncristiani U.Prognostic value of 24-h ambulatory blood pressure monitoring and of night/day ratio in non-diabetic, cardiovascular events free haemodialysis patients. Kidney Int 2005; 68:1294-1302.

15. Minutolo R, Agarwal R, Borrelli S, et al. Prognostic role of ambulatory blood pressure measurement in patients with nondialysis chronic kidney disease. Arch Intern Med 2011;171:1090-8.

16. Agarwal, R.; Andersen, M. J. Prognostic importance of ambulatory blood pressure recordings in patients with chronic kidney disease.Kidney International; Apr2006, Vol. 69 Issue 7, p1175

17. Davidson MB, Hix JK, Vidt DG, Brotman DJ. Association of impaired diurnal blood pressure variation with a subsequent decline in glomerular filtration rate. Arch Intern Med. 2006 Apr 24;166(8):846-52. 